\title{
Effect of intraperitoneal or intracerebroventricular injection of streptozotocin on learning and memory in mice
}

\author{
YANG ZHANG $^{1,2}$, RONG DING $^{1}$, SHANSHAN WANG ${ }^{1}$, ZHIYUN REN $^{1}$, LINGYAN XU $^{1}$, \\ XUNLE ZHANG ${ }^{1}$, JIAHUI ZHAO ${ }^{1}$, YU DING ${ }^{1}$, YU WU ${ }^{3}$ and YUESONG GONG ${ }^{1}$ \\ ${ }^{1}$ Jiangsu Key Laboratory of Therapeutic Material of Chinese Medicine, Department of Biopharmaceutics \\ and Food Science, School of Pharmacy, Nanjing University of Chinese Medicine, Nanjing, \\ Jiangsu 210023; ${ }^{2}$ Department of Anesthesiology, Xuzhou Medical University, Xuzhou, Jiangsu 221004; \\ ${ }^{3}$ Department of Nephrology, The First People's Hospital of Xuzhou, Xuzhou, Jiangsu 221002, P.R. China
}

Received April 10, 2018; Accepted July 6, 2018

DOI: $10.3892 /$ etm.2018.6487

\begin{abstract}
Alteration of behavior and PSD proteins in cerebral cortex and hippocampal synaptosome in the Alzheimer's disease (AD) mouse model were determined. AD was established by intraperitoneal injection of streptozotocin (STZ) in neonatal mice (intraperitoneal AD group) or intracerebroventricular injection of STZ in adult mice (intracerebroventricular AD group). Body weight and blood sugar level were measured. Following Morris water maze (MWM) test and fear-conditioning test, cerebral cortex and hippocampus tissues were collected and the levels of PSD95 and shank3 proteins in these tissues were measured by western blot analysis. The body weight was reduced and the blood sugar concentration was increased in the intraperitoneal AD group compared with the control group. In contrast, the body weight was reduced, while the blood sugar concentration was not increased in the intracerebroventricular AD group compared with the control group. Escape latency in both AD groups was extended compared with the control group. The freezing time in the intraperitoneal AD group was increased, while in the intracerebroventricular AD group, the freezing time was reduced. PSD95 and shank3 proteins in the cerebral cortex in both AD groups were decreased compared with the control group. PSD95 in the hippocampus was reduced in both AD groups compared with the control group. Shank3 in the hippocampus in the intracerebroventricular AD group was significantly reduced compared with the control group. Intraperitoneal
\end{abstract}

Correspondence to: Dr Yuesong Gong, Jiangsu Key Laboratory of Therapeutic Material of Chinese Medicine, Department of Biopharmaceutics and Food Science, School of Pharmacy, Nanjing University of Chinese Medicine, 138 Xianlin Avenue, Nanjing, Jiangsu 210023, P.R. China

E-mail:ygong@njucm.edu.cn

Key words: streptozotocin, intraperitoneal injection, intracerebroventricular injection, Alzheimer's disease mouse model, learning and memory, postsynaptic density, shank protein injection of STZ in neonatal mice led to elevated blood sugar, impaired spatial memory and enhanced emotional memory when they become adults. In contrast, intracerebroventricular injection of STZ in adults directly led to deteriorated spatial and emotional memory without alteration of blood sugar content, which could be associated with the changes of PSD95 and shank3 proteins in hippocampus.

\section{Introduction}

Alzheimer's disease (AD) is a neurodegenerative disease characterized by progressive cognitive impairment. The disease was officially named in 1906 and the pathological changes are mainly manifested as the loss of neurons and the formation of senile plaques and neurofibrillary tangles. In recent years, epidemiological and molecular pathology studies have shown that there is a close correlation between diabetes and AD. Both diabetes and AD are aging degenerative diseases with similar behavioral and pathological changes $(1,2)$. The correlation between diabetes and AD provides a new idea for the establishment of AD animal model.

Streptozotocin (STZ), a methylnitrosourea product, has antibacterial and antitumor properties and is capable of causing diabetes. It is a commonly used chemical compound for the study of the association between diabetes and AD (3). Peripheral blood vessel or intraperitoneal injection of STZ can selectively destroy pancreatic B cells, causing diabetes, which in turn induces symptoms of $\mathrm{AD}$ in mice. Intracerebroventricular injection of STZ can destroy the central insulin receptor phosphorylation, causing disorders of insulin signaling pathway (4). Consequently, it can cause brain glucose utilization and energy metabolism disorder, leading to learning and memory disorders and other AD symptoms (5).

Although both methods can induce the development of AD in mice (6), no comparison has been made yet between the behavior and the changes of synaptic PSD in the cortical and hippocampal neurons between intraperitoneal and intracerebroventricular injection models. Therefore, in this experiment, AD model was established by intraperitoneal and intracerebroventricular injection of STZ, respectively. Morris water maze (MWM) and fear-conditioning tests were used 
to determine the behavioral changes in the two models $(7,8)$. PSD95 and shank3 in cerebral cortex and hippocampus were also measured in order to identify the differences between the two models and discuss the potential underlying mechanisms that cause the differences.

\section{Materials and methods}

Animals. ICR $(\mathrm{n}=110), \mathrm{db} / \mathrm{db}(\mathrm{n}=10)$ and app/ps1 male mice $(\mathrm{n}=10)$ (weighing 18-20 g, aged 8-12 weeks) were purchased from the Research Institute of Model Animals at Nanjing University (Nanjing, China). Mice were housed in microisolator cages under specific pathogen-free conditions, fed with autoclaved food. Mice were handled under a protocol approved by the Institutional Animal Care and Use Committee of Nanjing University of Chinese Medicine (Nanjing, China).

Experimental protocol. The ICR newborn male mice were randomly selected for intraperitoneal injection of STZ (Beyotime Institute of Biotechnology, Shanghai, China). The mice were given a single subperitoneal injection of STZ $300 \mu 1$ for routine feeding with the mother mice. The control group was injected with the same amount of PBS buffer. The changes of body weight and blood glucose were detected at the 8th week. After the model was established successfully, the behavior test was carried out and the mice were sacrificed to detect the PSD protein in the cortex. In the intracerebroventricular injection of STZ model group, the adult ICR male mice were randomly selected at 7 weeks of age, and the lateral ventricle was injected with STZ $2 \mu 1$ once at body surface location. The control group was injected with the same amount of PBS buffer. After 1 week, the changes of body weight and blood glucose were measured. After the model was established successfully, the behavioral test was carried out, and then the mice were sacrificed to detect the PSD protein in the cortex. The $\mathrm{db} / \mathrm{db}$ male mice and the app/ps1 male mice had the behavioral test at the age of 8 weeks with routine feeding.

MWM test. Briefly, the mice were tested in a plastic water pool $\left(120 \mathrm{~cm}\right.$ in diameter) containing water at $22-24^{\circ} \mathrm{C}$ with distinctive spatial cues on all four walls. A platform $(8 \mathrm{~cm}$ in diameter) was submerged $1 \mathrm{~cm}$ under the water surface. The water pool was divided into four quadrants: northeast (NE); southeast (SE); northwest (NW); wouthwest (SW). The platform was placed in the SW quadrant as a target quadrant (TQ). The mice were dropped from the edge of the pool from four different locations (NW, SW, SE, NE) on the training day in a counter balanced order for 4 days. For each trial, the animal was allowed to swim until reaching the platform, where it would remain for $20 \mathrm{sec}$. If a mouse did not find the platform within $60 \mathrm{sec}$, we gently directed the animal to the platform, where it would remain for $20 \mathrm{sec}$. Finally, the testing trial from random quadrant was video tracked using camera to record the escape latency $(\mathrm{sec})$ to the platform.

Fear-conditioning test. Mice were placed into the chambers individually. After $3 \mathrm{~min}$, mice were subjected to electric foot-shocks $(0.75 \mathrm{~mA}, 2 \mathrm{sec}) 7$ times with tone $(2.5 \mathrm{kHz}, 85 \mathrm{~dB}$, $30 \mathrm{sec})$. The mice were then returned to their home cages. The next day, the mice were placed in the same chamber for $30 \mathrm{~min}$ without foot-shock. At the 3rd day, the mice were placed in the same chamber for $30 \mathrm{~min}$ with tone but no foot-shock. The behavior of the mice was recorded by a digital video camera. Continuous immobility for $>1 \mathrm{sec}$ was defined as freezing behavior. The duration of freezing was calculated as the ratio of freezing time to total recorded time (\%).

Western blot analysis. Western blot analysis of lysates of mouse cerebral cortex homogenates was performed as previously described (9). Briefly, fresh tissues were lysed on ice in the buffer containing $1 \mathrm{mM}$ PMSF, $0.2 \mathrm{U} / \mathrm{ml}$ aprotinin, and $1 \mathrm{mM}$ sodium orthovanadate. Protein concentrations of the samples were determined by use of the bicinchoninic acid protein assay kit. Total tissue lysate proteins $(30 \mu \mathrm{g}, 5 \mu \mathrm{g}$ protein loaded per lane) were loaded for 14\% SDS-PAGE, and the separated proteins were transferred onto nitrocellulose membranes by electroblotting. The membranes were incubated with primary antibodies overnight, washed, and then incubated with goat anti-rabbit or anti-mouse IgG conjugated to horseradish peroxidase $(1: 3,000-5,000)$ for $60 \mathrm{~min}$ at $20^{\circ} \mathrm{C}$. Protein bands were detected with the ECL SuperSignal reagent (EMD Millipore, Billerica, MA, USA). Relative band densities of the various proteins were measured from scanned films with ImageJ software.

Drugs, reagents, and antibodies. Mouse monoclonal Shank3 antibody (dilution, 1:500; cat. no. ab93607); mouse monoclonal PSD95 antibody (dilution, 1:500; cat. no. ab2723); rabbit polyclonal $\beta$-actin antibody (dilution, 1:1,000; cat. no. ab8227); secondary goat anti-rabbit (HRP) IgG antibody (dilution, 1:2,000; cat. no. ab6721) and secondary rabbit anti-mouse (HRP) IgG antibody (dilution, 1:2,000; cat. no. ab6728) were all purchased from Abcam (Cambridge, MA, USA).

Statistical analysis. One-way ANOVA and Student-NewmanKeuls test for post-hoc comparisons were used to determine differences between the control and the experimental groups. Student's t-test was performed for paired samples. Parameter changes between different groups over time were evaluated by a two-way ANOVA with repeated measurements. Data are expressed as means $\pm \mathrm{SE}$, and the differences between groups were considered significant if $\mathrm{P} \leq 0.05$.

\section{Results}

Body weight and blood sugar alteration. Neonatal male mice were injected with STZ $(100 \mathrm{mg} / \mathrm{kg})$ intraperitoneally and the body weight was reduced at 8 and 12 weeks of age compared with the control group (Fig. 1A and B). Blood glucose was increased compared with the control group and showed significant signs of diabetes (Fig. 1C and D). However, after the intracerebroventricular injection of STZ $(5 \mathrm{mg} / \mathrm{kg})$ in adult mice at the age of 7 weeks, body weight was decreased at the age of 8 and 12 weeks (Fig. 1E and F), while the blood glucose did not change significantly (Fig. $1 \mathrm{G}$ and $\mathrm{H}$ ).

Behavior alteration. MWM test showed that the escape latency (the time it takes to find the platform) in both intraperitoneal and intracerebroventricular groups was extended compared 

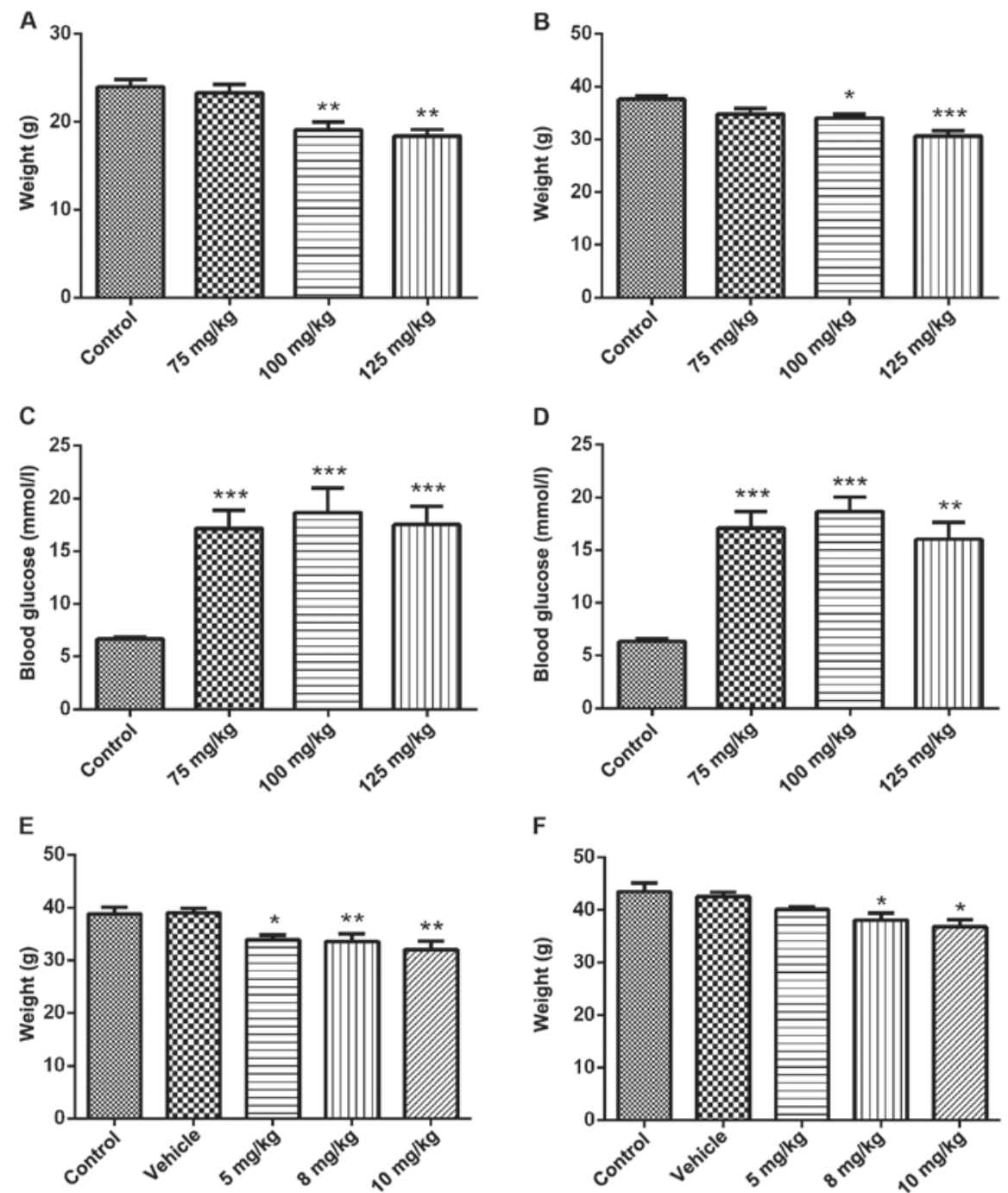

$\mathbf{F}$
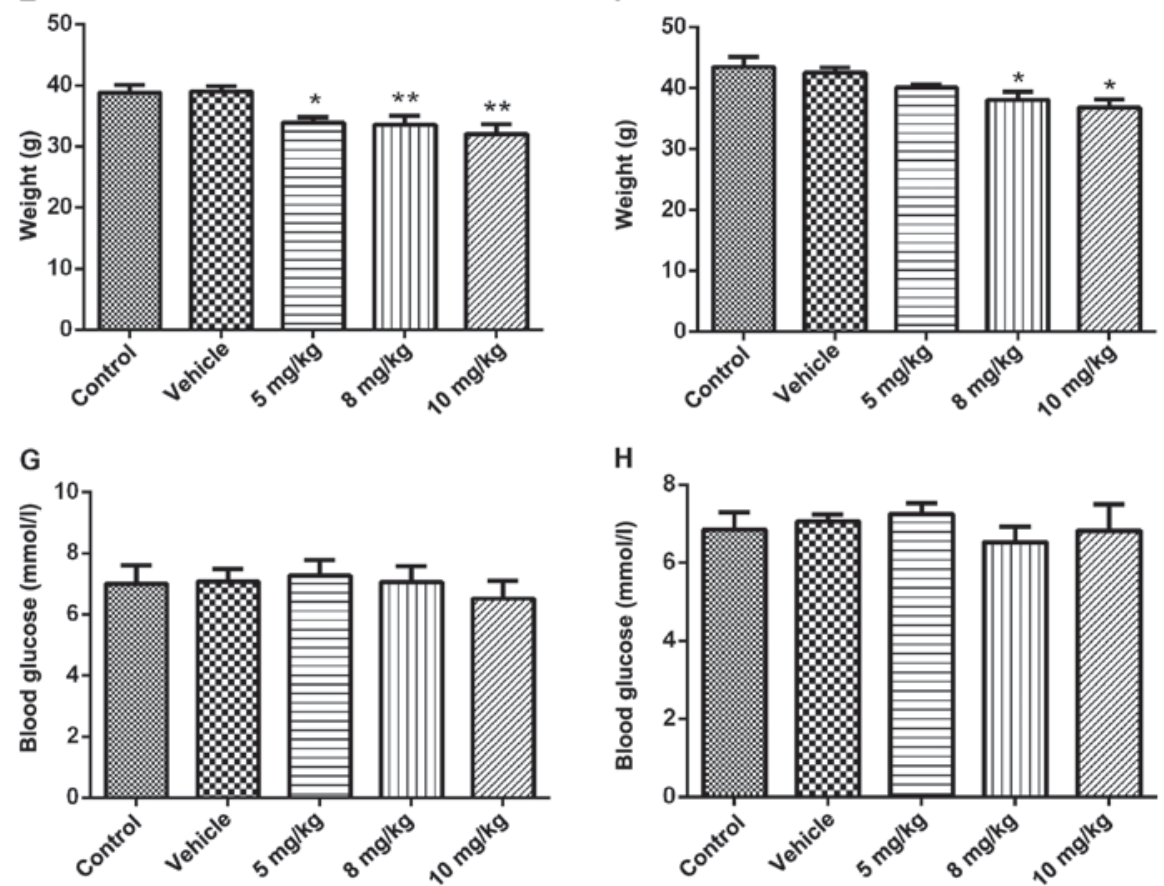

Figure 1. Body weight and blood sugar alteration. The body weight of neonatal male mice injected with STZ (75, $100 \mathrm{and} 125 \mathrm{mg} / \mathrm{kg}) \mathrm{intraperitoneally} \mathrm{at}$ (A) 8 weeks of age and (B) 12 weeks of age. Blood glucose of neonatal male mice injected with STZ (75, 100 and $125 \mathrm{mg} / \mathrm{kg}$ ) intraperitoneally at (C) 8 weeks of age and (D) 12 weeks of age. The body weight of adult male mice after intracerebroventricular injection with STZ (5, 8 and $10 \mathrm{mg} / \mathrm{kg})$ at the age of (E) 8 weeks and (F) 12 weeks. Blood glucose of adult male mice after intracerebroventricular injection with STZ (5, 8 and $10 \mathrm{mg} / \mathrm{kg}$ ) at the age of (G) 8 weeks and $(\mathrm{H}) 12$ weeks. ${ }^{*} \mathrm{P}<0.05 ;{ }^{* *} \mathrm{P}<0.01 ;{ }^{* * *} \mathrm{P}<0.001$ vs. control; $\mathrm{n}=10$. STZ, streptozotocin.

with the control group (Fig. 2A and C). Fear-conditioning test showed that the freezing time in the intraperitoneal group was increased (Fig. 2B), while in the intracerebroventricular group, the freezing time was reduced (Fig. 2D).

Alteration of PSD95 and shank3 proteins. PSD95 and shank3 proteins in the cerebral cortex in both intraperitoneal and intracerebroventricular groups were decreased compared with the control group (Fig. 3A-F). PSD95 in the hippocampus was reduced in both intraperitoneal and intracerebroventricular groups compared with the control group (Fig. 3G, I, $\mathrm{J}$ and $\mathrm{L}$ ). Shank3 in hippocampus in the intraperitoneal group was not significantly different from that in the control group (Fig. 3G and H). Shank3 in the hippocampus in the intracerebroventricular group was significantly reduced compared with the control group (Fig. 3J and K). 

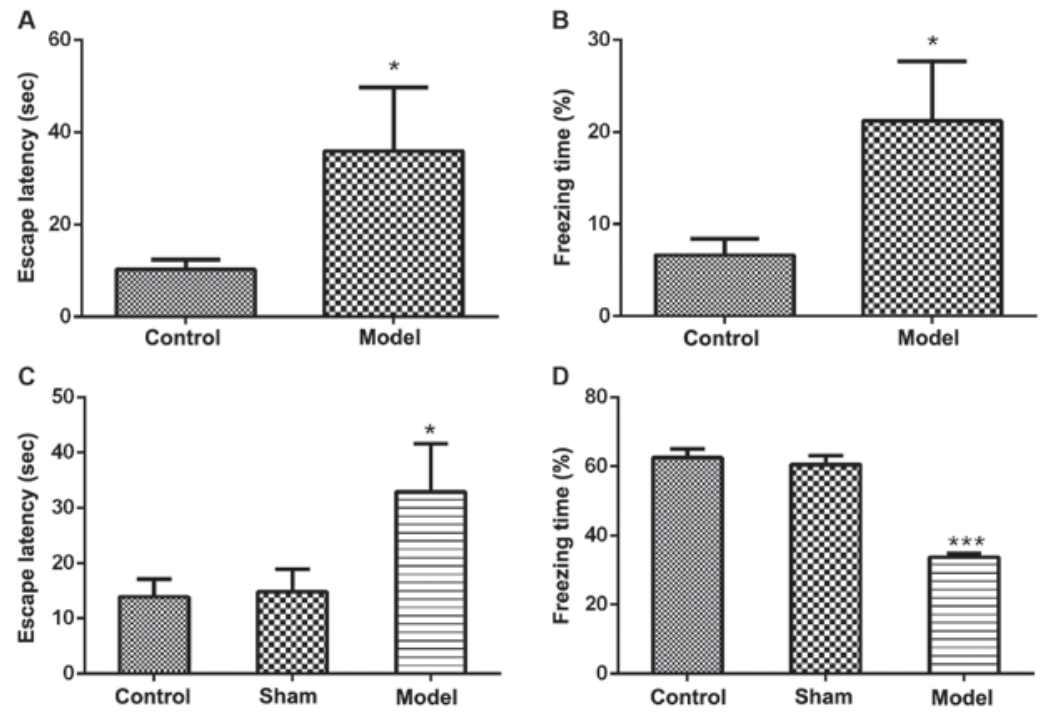

Figure 2. Behavior alteration. (A) The escape latency (the time it takes to find the platform) of MWM in intraperitoneal groups; (B) the freezing time of fear-conditioning test in intraperitoneal groups; (C) the escape latency of MWM in intracerebroventricular groups; (D) the freezing time of fear condition in intracerebroventricular groups; ${ }^{*} \mathrm{P}<0.05 ;{ }^{* * *} \mathrm{P}<0.001$ vs. control; $\mathrm{n}=10$. MWM, Morris water maze.

A

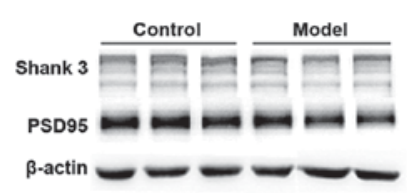

D

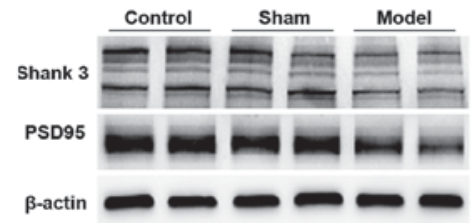

G

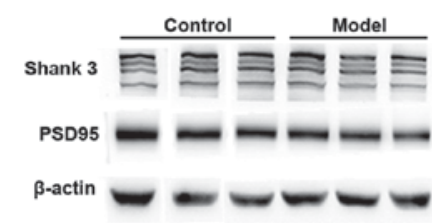

J

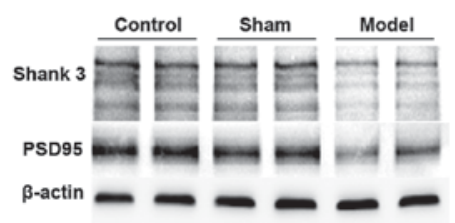

B

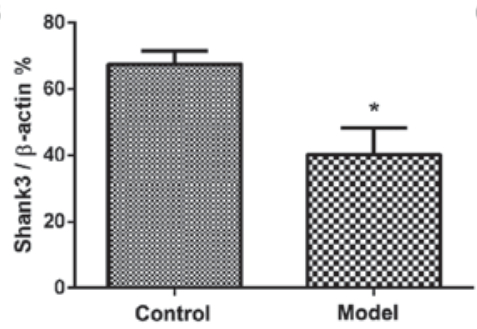

E

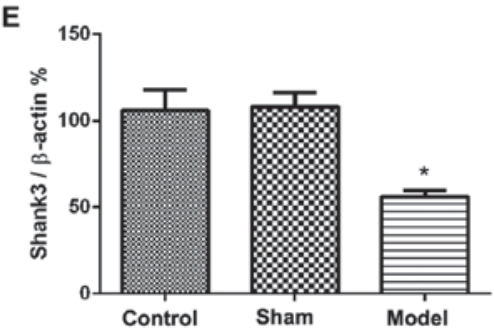

H

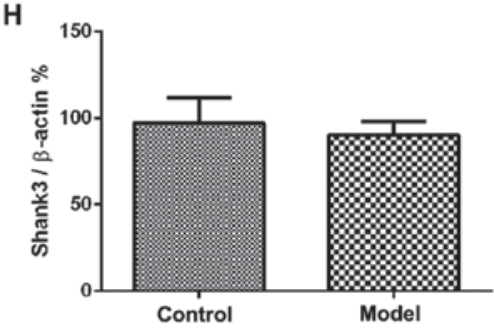

K

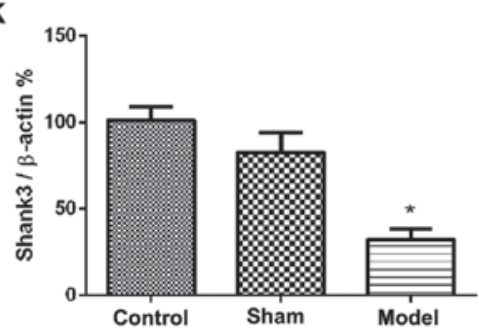

C

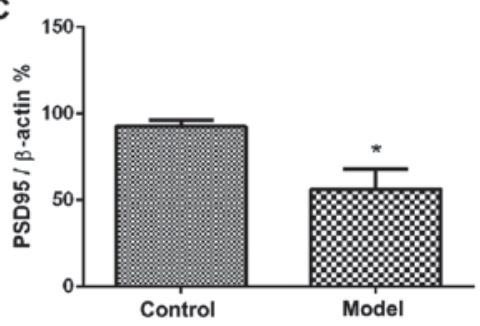

F
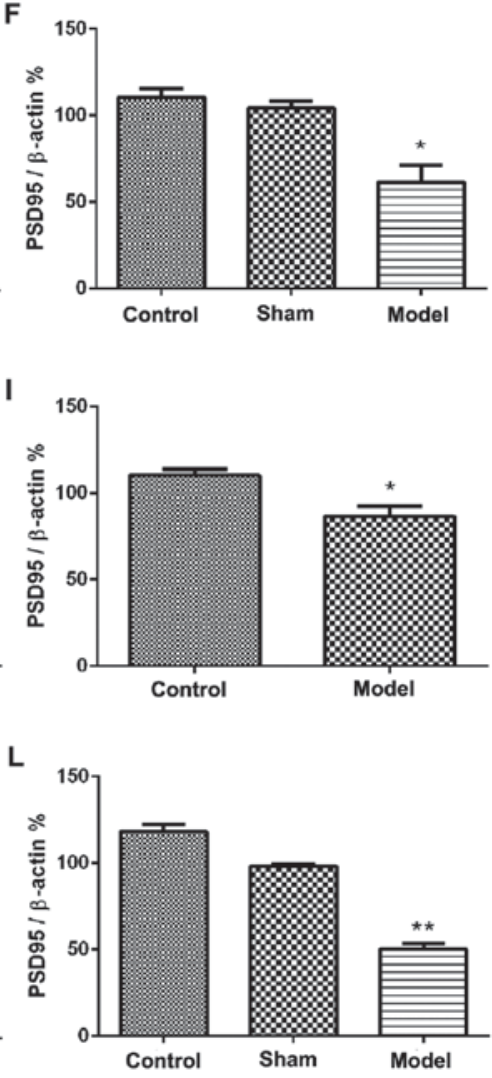

Figure 3. Alteration of PSD95 and shank3 proteins. PSD95 and shank3 proteins of the cerebral cortex in (A-C) intraperitoneal groups and (D-F) intracerebroventricular groups; PSD95 and shank3 proteins of the hippocampus in (G-I) intraperitoneal groups and (J-L) intracerebroventricular groups; ${ }^{*} \mathrm{P}<0.05 ;{ }^{* * *} \mathrm{P}<0.01$ vs. control. 

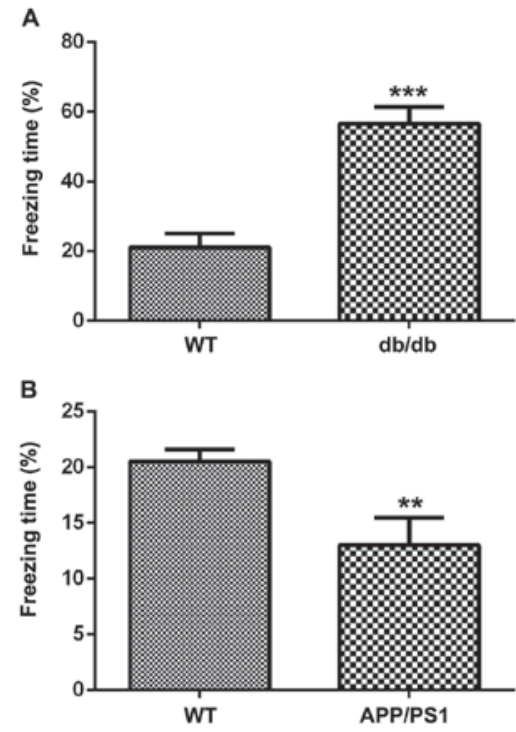

Figure 4. Fear-conditioning test in transgenic mice. The freezing time of fear-conditioning test (A) in $\mathrm{db} / \mathrm{db}$ mice (transgenic type 2 diabetic mice) and (B) in app/ps1 mice (transgenic AD mice). ${ }^{*} \mathrm{P}<0.05 ;{ }^{* *} \mathrm{P}<0.01$ vs. WT; $\mathrm{n}=10$. $\mathrm{AD}$, Alzheimer's disease.

Fear-conditioning test in transgenic mice. Fear-conditioning test showed that the freezing time in $\mathrm{db} / \mathrm{db}$ mice (transgenic type 2 diabetic mice) was longer than mice in the control group (Fig. 4A). The freezing time in the app/ps1 mice (transgenic $\mathrm{AD}$ mice) was reduced compared with mice in the control group (Fig. 4B).

\section{Discussion}

The main clinical manifestations of AD patients are cognitive decline and other mental and emotional abnormalities (1). They were classified into forgetting, mobility disorders, aggression and feeling upset, depression, anxiety and fear. Animal experiments usually showed a decrease in learning and memory ability, including spatial memory and emotional memory loss $(1,2)$.

Streptozotocin (STZ) can selectively destroy cells that have the function of synthesizing and secreting insulin. In the peripheral system (such as intraperitoneal injection), STZ can directly destroy pancreatic B cells and cause insulin resistance, thus inducing diabetes (3). STZ inducing AD-like pathological changes in rats or mice has also been considered to be a good AD experimental animal model. In the central nervous system, STZ can reduce the expression of cortical and hippocampal insulin receptor, thus undermining the insulin synthesis in the central nervous system. Consequently, the sensitivity of the central nervous system to peripheral insulin is reduced, leading to central nervous system dysfunction, and triggering AD symptoms (4). In addition, intraventricular injection with different STZ doses can induce emotional behavior changes in mice. Therefore, different STZ injection route can lead to different changes in blood glucose and behavior, including changes in spatial memory and emotions.

Conditional fear is the appearance of a neutral stimulus (such as light or sound) followed by a dangerous unconditional stimulus (usually a shock). After multiple times of trainings, neutral stimuli can be transformed into conditional stimuli. Formation of conditional fears triggers some behavioral and physiological reactions. These reactions are typically defensive responses (e.g., freezing or fearful jumping) that occur when an animal is exposed to danger or fear arising $(10,11)$. Different from spatial learning and memory, the essence of the formation of fear emotion memory is that some immediate stimuli trigger the activation of hippocampus (long-term potentiation) and amygdala, and the integration of all the three factors. This defensive response time reflects the speed of fear memory subsiding. Pathological mechanisms of AD are usually due to the reduction of this defensive response time, indicating a reduced emotional memory $(11,12)$. However, some studies have shown that the duration of fear and freezing was increased in diabetic mice caused by intravenous injection of STZ. It is presumed that the amygdala-hippocampus pathway is damaged and the sensitivity to fear is increased, manifesting more pronounced fear (12).

Postsynaptic density (PSD) is attached to the postsynaptic membrane and under the electron microscope this region has high electron density. PSD is an important structure that affects neuronal synaptic plasticity (13). As a scaffolding network of the postsynaptic membrane, PSD has glutamate receptors, scaffold proteins, and many signaling molecules. Shank3 is a scaffolding protein in PSD that promotes the formation of excitatory synapses and the development of dendritic spines $(14,15)$. PSD95 is a PSD scaffold protein that is associated with most neurotransmitters and other scaffold proteins. Proteomic analysis revealed significant changes in the PSD95 and shank3 proteins in the postsynaptic membrane of the cerebral cortex in patients with $\mathrm{AD}$, suggesting that these proteins may directly affect synaptic function at the molecular level $(16,17)$.

In this study, we showed that i) if the newborn mouse is given STZ intraperitoneally, it is not necessary to combine a high-fat and high-sugar diet to establish a diabetic model and induce AD symptoms with impaired learning and memory; ii) injection of STZ into the lateral ventricle of adult mice can directly induce the learning and memory impairment of AD model without causing changes in blood glucose; iii) both methods can cause spatial memory impairment in mice, but the conditional fear is different between the two methods: this difference is consistent with the results caused by simple transgenic animals; and iv) the difference in conditional fear between the two methods may be due to different STZ injection routes, leading to different levels of blood glucose and shank3 in the PSD structure of mouse hippocampal synaptosomes.

In summary, this study compared two STZ-induced AD models, and the results showed that intraperitoneal injection of STZ in newborn mice led to high blood glucose, impaired spatial memory, and increased emotional memory when they become adults. Intracerebroventricular injection of STZ in adult mice directly caused the loss of spatial and emotional memory without changes in blood glucose, which may be closely related to the changes of the shank 3 protein in the hippocampal synaptosomes. The mechanism needs to be further studied to better illustrate the similarities and differences between the two models and provide sufficient scientific evidence on diabetic and AD studies. 


\section{Acknowledgements}

We would like to thank Haitong Zhang for her assistance with the experiments.

\section{Funding}

This study was financially supported by the Priority Academic Program Development (PAPD) fund of the Jiangsu Higher Education Institution (Dr Y. Gong).

\section{Availability of data and materials}

The datasets used and/or analyzed during the present study are available from the corresponding author on reasonable request.

\section{Authors' contributions}

YZ conceived the study and drafted the manuscript. RD and SW performed the animal behavior experiments and the data analysis; ZR, LX and YW were responsible for the brain tissue protein assay; XZ, JZ, YD and YG detected the body weight and blood sugar of animals; YW and YG revised the manuscript. All authors read and approved the final manuscript.

\section{Ethics approval and consent to participate}

The study was approved by the Institutional Animal Care and Use Committee of Nanjing University of Chinese Medicine (Nanjing, China).

\section{Patient consent for publication}

Not applicable.

\section{Competing interests}

The authors declare that they have no competing interests.

\section{References}

1. Sorial ME and El Sayed NSED: Protective effect of valproic acid in streptozotocin-induced sporadic Alzheimer's disease mouse model: Possible involvement of the cholinergic system. Naunyn Schmiedebergs Arch Pharmacol 390: 581-593, 2017.

2. Li D, Huang Y, Cheng B, Su J, Zhou WX and Zhang YX Streptozotocin induces mild cognitive impairment at appropriate doses in mice as determined by long-term potentiation and the Morris water maze. J Alzheimers Dis 54: 89-98, 2016.

3. Singh JC, Kakalij RM, Kshirsagar RP, Kumar BH, Komakula SS and Diwan PV: Cognitive effects of vanillic acid against streptozotocin-induced neurodegeneration in mice. Pharm Biol 53: 630-636, 2015.
4. Javed H, Vaibhav K, Ahmed ME, Khan A, Tabassum R, Islam F, Safhi MM and Islam F: Effect of hesperidin on neurobehavioral, neuroinflammation, oxidative stress and lipid alteration in intracerebroventricular streptozotocin induced cognitive impairment in mice. J Neurol Sci 348: 51-59, 2015.

5. Pandey SP, Singh HK and Prasad S: Alterations in hippocampal oxidative stress, expression of AMPA Receptor GluR2 subunit and associated spatial memory loss by Bacopa monnieri Extract (CDRI-08) in streptozotocin-induced diabetes mellitus type 2 mice. PLoS One 10: e0131862, 2015.

6. Kumar A and Singh N: Calcineurin inhibitors improve memory loss and neuropathological changes in mouse model of dementia. Pharmacol Biochem Behav 153: 147-159, 2017.

7. Sommer C, Roth SU and Kiessling M: Kainate-induced epilepsy alters protein expression of AMPA receptor subunits GluR1, GluR2 and AMPA receptor binding protein in the rat hippocampus. Acta Neuropathol 101: 460-468, 2001.

8. Stragier E, Martin V, Davenas E, Poilbout C, Mongeau R, Corradetti $\mathrm{R}$ and Lanfumey L: Brain plasticity and cognitive functions after ethanol consumption in C57BL/6J mice. Transl Psychiatry 5: e696, 2015.

9. Zhang Y, Liu G, Dull RO, Schwartz DE and Hu G: Autophagy in pulmonary macrophages mediates lung inflammatory injury via NLRP3 inflammasome activation during mechanical ventilation. Am J Physiol Lung Cell Mol Physiol 307: L173-L185, 2014.

10. Poitout V and Robertson RP: Minireview: Secondary beta-cell failure in type 2 diabetes - a convergence of glucotoxicity and lipotoxicity. Endocrinology 143: 339-342, 2002.

11. Ikeda H, Ikegami M, Kai M and Kamei J: Cannabinoid functions in the amygdala contribute to conditioned fear memory in streptozotocin-induced diabetic mice: Interaction with glutamatergic functions. Exp Neurol 269: 233-241, 2015.

12. Portha B, Giroix MH, Serradas P, Morin L, Tormo MA and Bailbe D: Cellular basis for glucose refractoriness of pancreatic B-cells in non insulin dependent diabetes. In: Frontiers of Insulin Secretion and Pancreatic B Cell Research. Flatt PR and Lenzen S (eds). Smith-Gordon and Co., Ltd., Huntingdon, Cambridgeshire, pp461-472, 1994.

13. Durand CM, Betancur C, Boeckers TM, Bockmann J, Chaste P, Fauchereau F, Nygren G, Rastam M, Gillberg IC, Anckarsäter H, et al: Mutations in the gene encoding the synaptic scaffolding protein SHANK3 are associated with autism spectrum disorders. Nat Genet 39: 25-27, 2007.

14. Gong Y, Chang L, Viola KL, Lacor PN, Lambert MP, Finch CE, Krafft GA and Klein WL: Alzheimer's disease-affected brain: Presence of oligomeric A beta ligands (ADDLs) suggests a molecular basis for reversible memory loss. Proc Natl Acad Sci USA 100: 10417-10422, 2003.

15. Gong Y and Lippa CF: Review: Disruption of the postsynaptic density in Alzheimer's disease and other neurodegenerative dementias. Am J Alzheimers Dis Other Demen 25: 547-555, 2010.

16. Gong Y, Lippa CF, Zhu J, Lin Q and Rosso AL: Disruption of glutamate receptors at Shank-postsynaptic platform in Alzheimer's disease. Brain Res 1292: 191-198, 2009.

17. Xu L, Ren Z, Chow FE, Tsai R, Liu T, Rizzolio F, Boffo S, Xu Y, Huang S, Lippa CF, et al: Pathological role of peptidyl-prolyl isomerase Pin1 in the disruption of synaptic plasticity in Alzheimer's disease. Neural Plast 2017: 3270725, 2017.

(i) $(-)$ This work is licensed under a Creative Commons Attribution-NonCommercial-NoDerivatives 4.0 International (CC BY-NC-ND 4.0) License. 